INTERSTITIAL LUNG DISEASE

\title{
Relationship between histopathological features and the course of idiopathic pulmonary fibrosis/usual interstitial pneumonia
}

\author{
L Tiitto, R Bloigu, U Heiskanen, P Pääkkö, V L Kinnula, R Kaarteenaho-Wiik

See end of article for authors' affiliations

Correspondence to: Dr L Tiitto, Department of Internal Medicine, P O Box 5000 (Kajaanintie 50), FIN-90014 University of Oulu, Finland; Leena. Tiiito@oulu.fi

Received

14 November 2005 Accepted 17 May 2006

Published Online First

12 June 2006
Background: Fibroblastic focus (FF) is the typical histopathological feature of idiopathic pulmonary fibrosis (IPF)/usual interstitial pneumonia (UIP). A study was undertaken to analyse FF at diagnosis, to analyse the histopathological findings at necropsy, and to examine their association with the course of the disease. Methods: A retrospective study was made of 76 UIP cases collected over a period of 30 years from one university hospital; 64 had idiopathic IPF. The surface area of one slide of each lung biopsy specimen was defined by image analysis and the total number of FF was quantified. The histological features of necroscopic lung samples were re-analysed in 11 cases. Clinical follow up information was obtained from the registers.

Results: Patients with $\leqslant 50 \mathrm{FF} / \mathrm{cm}^{2}(\mathrm{n}=34)$ in the lung biopsy specimen had a median survival of 89 months (95\% Cl 38 to 140) compared with 49 months (95\% Cl 36 to 62 ) in those with $>50 \mathrm{FF} / \mathrm{cm}^{2}$ $(n=42, p=0.0358)$. Diffuse alveolar damage (DAD) was detected in 10 necropsy samples and almost prevented the histopathological confirmation of UIP in six cases. Accumulation of neutrophils occurred in nine cases. There was no association between FF at diagnosis and DAD at necropsy, or between FF and exacerbation of the disease before death.

Conclusions: The number of FF in lung samples before death is associated with poor survival but not with $D A D$, which is a common feature in necropsy specimens of patients with UIP. FF cannot predict an acute exacerbation of IPF. type diop diopathic pulmonary fibrosis (IPF) is the most common type of idiopathic interstitial pneumonia, with histopathological characteristics of usual interstitial pneumonia (UIP). In general there is a progressive deterioration of lung function parameters in IPF/UIP that ultimately leads to respiratory insufficiency and death within 4-6 years. ${ }^{12}$ Although IPF/UIP often has a chronic and progressive course, another feature of the disease is the occurrence of unpredictable rapid exacerbations without any apparent infection that leads to death within a few weeks in most patients. ${ }^{3}$ The particular pathological features associated with these terminal events are poorly understood. ${ }^{4-6}$ It is already known that fibroblast focus (FF), a typical finding in the histopathology of UIP, is associated with a poor prognosis. ${ }^{7-9}$ There are also reports of histopathological features of diffuse alveolar damage (DAD) in necroscopic lung tissue of patients with UIP. ${ }^{4}{ }^{10}{ }^{11}$ However, previous studies have focused mainly on lung pathology rather than on the clinical course of the disease. No studies have been undertaken to examine whether these two apparently separate findings are somehow associated with each other. It is also unknown whether rapid exacerbations of IPF/UIP are associated with the number of FF. Previous studies have analysed FF in selected areas of lung specimens rather than systematically analysing whole histopathological samples. ${ }^{7}$

We examined material from all cases of UIP treated at our hospital during the past 30 years. The samples were reevaluated and the number of FF in the whole specimen quantified. Every histopathological necroscopic lung sample available from these cases was evaluated for the occurrence of DAD and other features such as the existence of UIP. ${ }^{12}$ The necropsy samples were compared with the corresponding lung biopsy specimens taken before death and the course of the disease.

\section{METHODS}

Patients, handling and analysis of specimens

Seventy six lung biopsy specimens with histopathological characteristics typical of UIP (open or thoracoscopic biopsies) were obtained from the files of the Department of Pathology, Oulu University Hospital, Finland for the period between January 1973 and January 2003. The surgical lung biopsies were re-evaluated by two pathologists (RK-W, PP). The histopathological diagnosis was based on light microscopic evaluations. ${ }^{13}$

The biopsy material had been fixed in 10\% formalin under vacuum or perfused by injecting the fixative into the bronchioles and embedded in paraffin. ${ }^{14}$ Sections $4 \mu \mathrm{m}$ thick were stained with Alcian blue-periodic acid Schiff (AB-PAS) and haematoxylin/eosin (HE). The total numbers of newly formed connective tissue bundles (known as FF) containing fibroblasts/myofibroblasts were analysed independently by two pathologists (RK-W, PP). The surface area of lung tissue in one slide of each case was defined by image analysis (MC ID-M4 for Widows 3.0 Rev 1.1; Imaging Research Inc, Brock University, St Catherines, Ontario, Canada) and the numbers of FF were divided into two subgroups $\left(\leqslant 50\right.$ or $>50 \mathrm{FF} / \mathrm{cm}^{2}$ ) with a similar number of cases in each.

Necroscopic examination was carried out in 11 cases of UIP. Lung tissue samples were taken from all five lobes in 10 cases and from only the right lung lobes in the remaining case. The samples were re-analysed by HE staining. The histological features including UIP, squamous type metaplastic alveolar epithelium, accumulation of intra-alveolar neutrophils, and hyaline membranes were classified independently as negative

Abbreviations: CRP, C-reactive protein; DAD, diffuse alveolar damage; FF, fibroblastic focus; IPF, idiopathic pulmonary fibrosis; TLCO, carbon monoxide transfer factor; UIP, usual interstitial pneumonia 
$(-)$ or positive $(+)$ by two pathologists (RK-W, PP). DAD was quantified as the extent of lung tissue involvement as follows: no evidence of DAD $(-)$, focal patches of DAD $(+)$, widespread DAD $(++)$.

The demographic data collected included age at the time of the biopsy, sex, smoking history, other connective tissue diseases, date and type of biopsy, treatment, date and cause of death. Lung function parameters included spirometry and single breath carbon monoxide transfer factor (TLCO).

Survival times from the initial visit due to symptoms and from the time of the lung biopsy were recorded. The end point of the study was the last visit before 1 January 2003 or death. The appearance of pneumonia-like radiological findings and raised C- reactive protein (CRP) levels were obtained from the records of the 11 patients who underwent a necroscopic examination.

Criteria for accelerated deterioration-that is, an acute exacerbation of IPF-included exacerbation of dyspnoea during the previous month, new diffuse pulmonary opacities on the chest radiograph, a decrease in arterial oxygen tension $\left(\mathrm{PaO}_{2}\right)$ of more than $1.33 \mathrm{kPa}(10 \mathrm{~mm} \mathrm{Hg})$ under similar conditions, and the absence of apparent infectious agents or heart failure. ${ }^{15}$

The study protocol was approved by the ethical committee of Oulu University Hospital.

\section{Statistical analysis}

Statistical analyses were performed with SPSS for Windows software (SPSS Inc, Chicago, IL, USA). Survival was estimated using the Kaplan-Meier method. The log rank statistic was used to compare survival among groups. Median survival was used whenever possible. p values $<0.05$ were considered statistically significant. The inter-observer reliability between the two pathologists was investigated using Cohen's kappa statistics. ${ }^{16}$ Since no linear correlation between the number of FF and survival was observed, a receiver operating characteristic (ROC) curve was used to establish the cut-off value (that is, the number of FF) at which the material was divided into two subsets. ${ }^{17}$

\section{RESULTS}

\section{Patient characteristics and outcome}

A total of 64 patients with idiopathic UIP and 12 patients with UIP in combination with a connective tissue disease such as rheumatoid arthritis $(n=4)$, scleroderma $(n=4)$, dermatomyositis $(n=3)$, and mixed connective tissue disease $(n=1)$ were included in the study. There were 42 men $(55.3 \%)$ and 34 women $(44.7 \%)$. The median survival of the whole group after the first visit to hospital with symptoms was 91 months (95\% CI 62 to 120), and after a lung biopsy was performed was 59 months (95\% CI 44 to 74 ). The
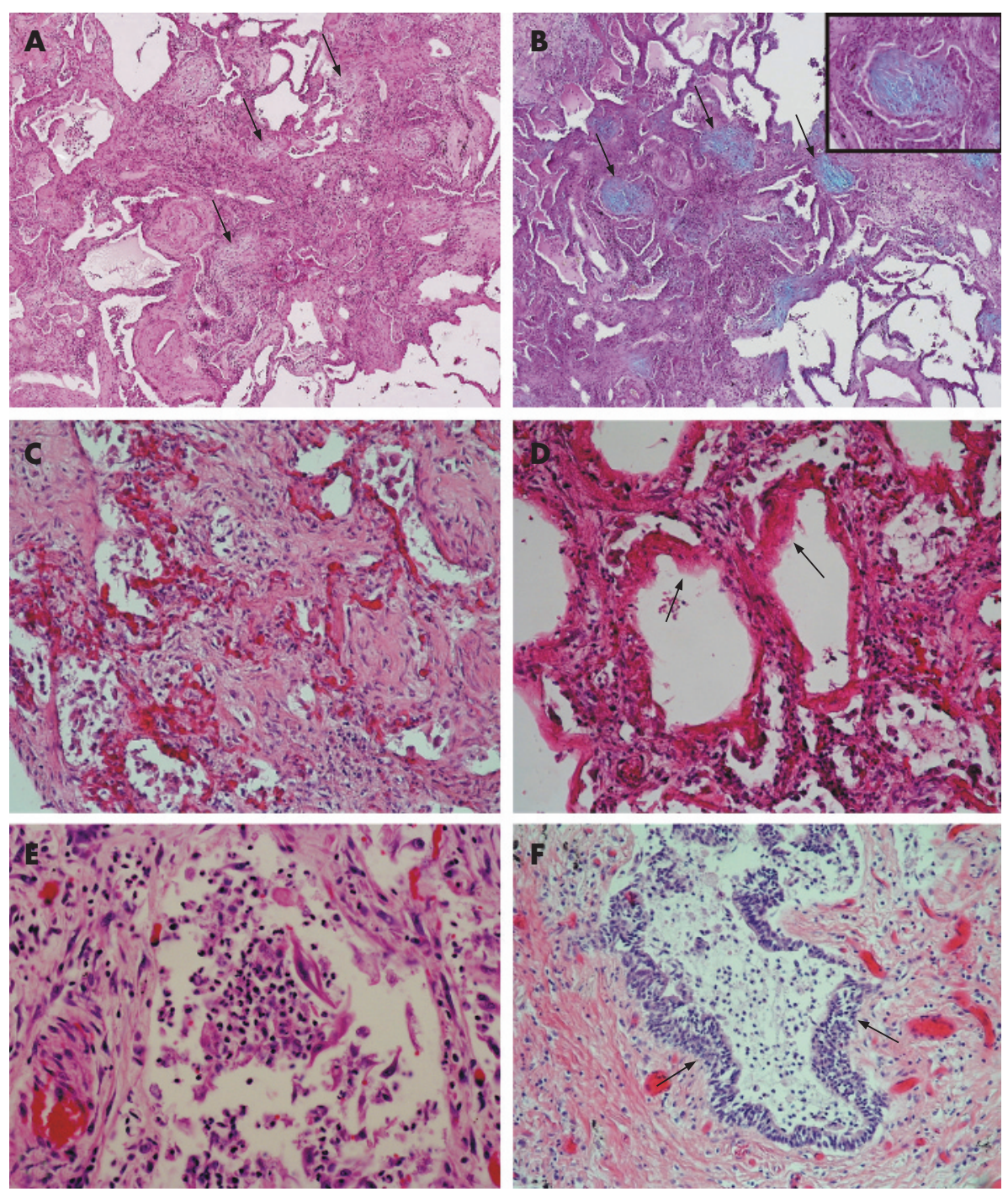

Figure 1 (A) Fibroblast foci (arrows) in usual interstitial pneumonia (UIP) stained with haematoxylin-eosin (HE); original magnification $\times 25.5$. (B)

Fibroblast foci (arrows) in UIP stained with Alcian blue-periodic acid Schiff

(AB-PAS); original magnification

$\times 25.5$. Inset: a fibroblast focus at higher magnification; original magnification $\times 2.8$. (C) Diffuse alveolar damage (DAD) in a necroscopic lung sample from a patient with idiopathic UIP; original magnification $\times 63.8$. (D) Hyaline membranes (arrows) of DAD in a necroscopic sample from a patient with idiopathic UIP; original magnification $\times 63.8$. (E) Intra-alveolar neutrophils in a necroscopic sample from a patient with idiopathic UIP; original magnification $\times 255$. (F) Metaplastic squamous type alveolar epithelium (arrows) in a necroscopic sample from a patient with idiopathic UIP; original magnification $\times 63.8$. 


\begin{tabular}{|c|c|c|c|}
\hline Variable & $\begin{array}{l}\text { Idiopathic UIP } \\
(n=64)\end{array}$ & $\begin{array}{l}\mathrm{UIP}+\mathrm{CTD} \\
(\mathrm{n}=12)\end{array}$ & $\begin{array}{l}\text { Total } \\
(n=76)\end{array}$ \\
\hline $\begin{array}{l}\text { Median survival after diagnosis } \\
\text { (months) }\end{array}$ & 69 (47 to 91$)$ & $232^{*}$ (182 to 281$)$ & 91 (62 to 120 ) \\
\hline $\begin{array}{l}\text { Median survival after biopsy } \\
\text { (months) }\end{array}$ & $49(40$ to 58$)$ & $223^{*}(167$ to 280$)$ & 59 (44 to 74$)$ \\
\hline $1-50 \mathrm{FF} / \mathrm{cm}^{2}$ & $\begin{array}{l}60(49 \text { to } 71) \\
(n=28)\end{array}$ & $\begin{array}{l}217^{*}(185 \text { to } 249) \\
(n=6)\end{array}$ & $\begin{array}{l}89(38 \text { to } 140) \\
(n=34)\end{array}$ \\
\hline$>50 \mathrm{FF} / \mathrm{cm}^{2}$ & $\begin{array}{l}44(30 \text { to } 58) \\
(n=36)\end{array}$ & $\begin{array}{l}201^{*}(100 \text { to } 301) \\
(n=6)\end{array}$ & $\begin{array}{l}49(36 \text { to } 62) \\
(n=42)\end{array}$ \\
\hline
\end{tabular}

diagnosis was based on 42 open thoracotomies (55.3\%) with median survival time of 51 months after biopsy (95\% CI 36 to $66)$ and 34 thoracoscopies $(44.7 \%)$ with median survival of 71 months (95\% CI 43 to 99 ), $\mathrm{p}=0.3014$. The mean age at the time of biopsy was 56.7 years (range 21-77). The age of the patients at the time of the biopsy was significantly correlated with the median survival after the biopsy ( 211 months (95\% CI 109 to 313 ) in patients aged $\leqslant 50$ years compared with 51 months (95\% CI 42 to 60 ) in those aged $>50$ years, $\mathrm{p}=0.006$ ).

The median survival after the lung biopsy did not change significantly over the period of the study; eight patients died in the 1970s (median survival 47 months (95\% CI 3 to 91)), 19 in the 1980s (median survival 60 months (95\% CI 17 to $105)$ ), and 23 in the 1990s (median survival 63 months (95\% CI 42 to 84)). Only one patient had died in the 2000 s by the end of the study, having survived for 10 months after lung biopsy.

By January 2003, 51 of the 76 patients $(67.1 \%)$ included in the study had died $(67.1 \%)$. Forty three died of UIP (41 of whom had idiopathic UIP), four died of lung cancer (two squamous cell carcinomas and two small cell carcinomas), three patients died from myocardial infarction, and one from gastrointestinal bleeding. Necropsy was performed in 11 cases, all of whom had idiopathic UIP as the main cause of death.

The histopathological verification of UIP led to a change in treatment in 58 cases $(76.8 \%)$ with no statistical effect on survival. The 58 patients for whom treatment was changed had a median survival of 61 months (95\% CI 37 to 85), nine patients in whom there was no change in medication had a median survival of 85 months (95\% CI 38 to 132), and nine patients who received no treatment had a median survival of 49 months (95\% CI 26 to 72 ). Corticosteroids were added in 45 cases, 16 of which also received additional azathioprine,

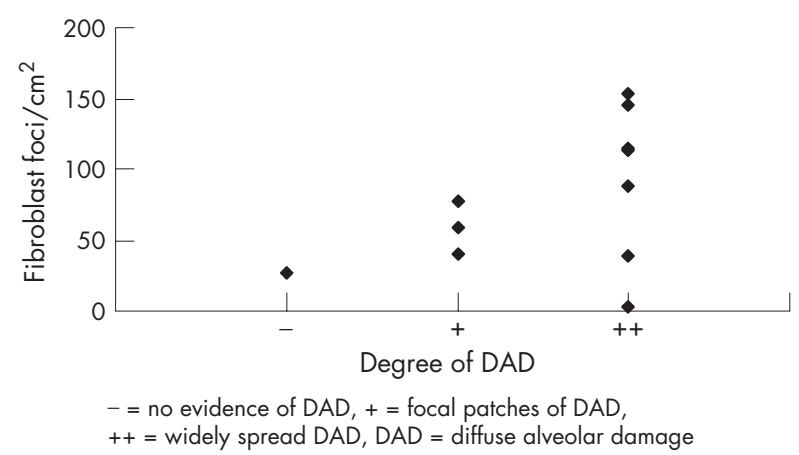

Figure 2 Association between number of fibroblast foci/ $\mathrm{cm}^{2}$ and diffuse alveolar damage (DAD) in UIP/IPF.

and cyclophosphamide was added in four cases. Two patients underwent lung transplantation because of UIP.

\section{Histopathological findings of lung biopsies and correlation with survival}

FFs were observed in all cases (fig $1 \mathrm{~A}$ and B). The mean area of the material analysed was $1.64 \mathrm{~cm}^{2}$. The number of FF varied from 2 to $327 / \mathrm{cm}^{2}$ with a mean of $76 \mathrm{FF} / \mathrm{cm}^{2}$ in patients with idiopathic UIP and $50 \mathrm{FF} / \mathrm{cm}^{2}$ in those with UIP and connective tissue disease. The number of patients with idiopathic UIP with $<50 \mathrm{FF} / \mathrm{cm}^{2}$ was 28 , compared with 36 with $>50 \mathrm{FF} / \mathrm{cm}^{2}$; there were six patients in each subgroup with connective tissue disease. As expected, patients with fewer FF had a better prognosis. Using the Kaplan-Meier method, patients with $\leqslant 50 \mathrm{FF} / \mathrm{cm}^{2}(\mathrm{n}=34)$ had a median survival of 89 months (95\% CI 38 to 140) compared with 49 months $\left(95 \%\right.$ CI 36 to 62 ) in those with $>50 \mathrm{FF} / \mathrm{cm}^{2}$

Table 2 Patient information and histopathological findings of necropsy samples from 11 patients with IPF/UIP

\begin{tabular}{|c|c|c|c|c|c|c|}
\hline Patient no & $\mathrm{Age}^{*} / \mathrm{Sex}$ & DAD† & $\begin{array}{l}\text { Hyaline } \\
\text { membranes }\end{array}$ & UIP‡ & $\begin{array}{l}\text { Metaplastic squamous } \\
\text { epithelium }\end{array}$ & $\begin{array}{l}\text { Intra-alveolar } \\
\text { neutrophils }\end{array}$ \\
\hline 1 & $61 / M$ & ++ & + & $(+)$ & + & + \\
\hline 2 & $37 / M$ & ++ & + & + & + & + \\
\hline 3 & $53 / \mathrm{M}$ & + & + & $(+)$ & + & + \\
\hline 4 & $67 / M$ & + & + & $(+)$ & + & - \\
\hline 5 & $69 / \mathrm{F}$ & - & - & + & + & + \\
\hline 6 & $53 / \mathrm{F}$ & + & + & + & + & - \\
\hline 7 & $56 / \mathrm{F}$ & + & ++ & $(+)$ & + & + \\
\hline 8 & $45 / M$ & ++ & + & $(+)$ & + & + \\
\hline 9 & $58 / \mathrm{F}$ & + & ++ & $(+)$ & - & + \\
\hline 10 & $54 / M$ & + & + & + & + & + \\
\hline 11 & $58 / M$ & + & + & + & + & + \\
\hline
\end{tabular}

*Age in years at time of death.

TDAD, diffuse alveolar damage: - , no evidence of $D A D ;+$, focal patches of $D A D ;++$, widely spread DAD

fUIP, usual interstitial pneumonia: $(+)$, histopathological features of UIP covered by DAD. 


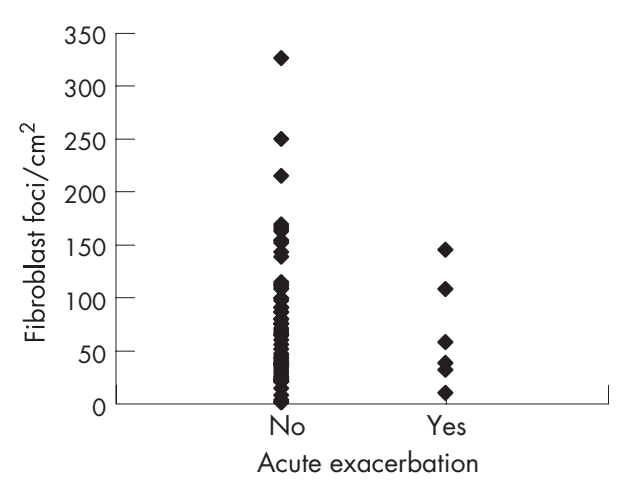

Figure 3 Association between number of fibroblast foci $/ \mathrm{cm}^{2}$ and acute exacerbation of IPF/UIP.

( $\mathrm{n}=42, \mathrm{p}=0.0358$, (table $\mathrm{l}$ ). The survival of patients with idiopathic UIP and connective tissue disease is shown in table 1 . The inter-observer repeatability between the scores of the two pathologists was moderate $(\kappa=0.568)$.

There was a significant negative correlation between TLCO and the number of FF (Spearman $\sim 0.302, p=0.009$ ), patients with a lower TLCO more often having a higher number of FF in their lung biopsy specimens.

\section{Histopathological findings of necroscopic samples}

Histopathological findings of necropsy material revealed DAD with hyaline membranes in 10 of 11 cases (fig IC and 1D). However, the extent of DAD varied from case to case. In three cases DAD was observed in focal patches while in seven it was observed widely throughout the whole lung tissue. In six cases DAD was so strong that it nearly prevented the typical histological features of UIP being seen. Post mortem analysis revealed neutrophil infiltrates in nine of the 11 cases (fig $1 E$ ). Squamous type metaplastic alveolar epithelium could be detected in 10 cases (fig $\mathrm{lF}$ ). In six patients there were clinical signs of pneumonia such as chest radiographic findings or increased CRP levels, but histopathological analyses of the necroscopic samples of these patients revealed typical histopathological features of pneumonia in only two cases. On the other hand, two other patients with typical characteristics of pneumonia in their necropsy lung samples did not have any changes in chest radiographic findings or raised CRP levels before death. The histopathological findings of the necroscopic specimens are summarised in table 2 .

\section{Association between DAD and FF}

When DAD was categorised and correlated with FF, there appeared to be no significant association between them. Generally, DAD was found in biopsy samples from those with low and high numbers of FF (fig 2).

\section{Acute exacerbations before death and association with FF and extent of DAD}

Acute exacerbations before death were assessed according to Akira et al. ${ }^{15}$ Seven patients fulfilled all the criteria of accelerated deterioration of IPF; in a further two cases an acute exacerbation was presumed because the $\mathrm{PaO}_{2}$ value from the last visit was not available in one case and there were problems in assessing the chest radiograph and excluding infection in another. ${ }^{15}$ In the present study, 43 of the 51 who had died had IPF/UIP as the cause of death, nine of whom (20.9\%) had an acute exacerbation of IPF/UIP before death. When the numbers of FF were compared with the acute exacerbations before death, no significant correlation was found (fig 3).
Table 3 Numbers of IPF/UIP patients classified by the occurrence of an acute exacerbation and the extent of DAD

\begin{tabular}{lll}
\hline Extent of DAD & $\begin{array}{l}\text { Accelerated } \\
\text { exacerbation } \\
\text { of IPF }\end{array}$ & $\begin{array}{l}\text { No accelerated } \\
\text { exacerbation } \\
\text { of IPF }\end{array}$ \\
\hline Widespread & 1 & 6 \\
Focal patches & 2 & 1 \\
No evidence & 0 & 1 \\
\hline
\end{tabular}

There was no correlation between the occurrence of an accelerated exacerbation of IPF/UIP and the extent of DAD, since six of 11 patients had widespread DAD in their necroscopic samples without clinical signs of an acute exacerbation before death (table 3 ).

\section{DISCUSSION}

To our knowledge, this is the first study to use exact numbers of FF in UIP tissue samples rather than calculated indices or scores of FF. Furthermore, a possible correlation between FF and both acute exacerbations of IPF/UIP before death and necroscopic findings for the same patients was examined. The number of FF generally correlated with median survival but not with acute exacerbations of IPF/UIP. Although DAD was a typical finding in the necroscopic samples, it did not correlate with the presence of FF in biopsy specimens taken before death.

Although previous studies have examined the presence of FF in UIP, ${ }^{7} 1819$ there has been no detailed analysis of their numbers in the whole microscopic slide specified by morphometry. Nicholson and co-authors scored the number of FF from one to three standard areas to make an index and found a correlation between the increasing extent of FF and mortality. ${ }^{9}$ King and co-workers found an association between increasing granulation/young connective tissue, including the semi-quantitative grading results of the amount of FF, and decreased survival in UIP. ${ }^{7}$ The present results are in full agreement with these previous investigations. In contrast to earlier studies, the lung biopsies in our study were evaluated using AB-PAS staining which was found to be simple, sensitive and repeatable. It can therefore be recommended for use in routine clinical analysis.

We included and re-evaluated 76 cases of UIP from a period of 30 years, including all lung specimens of each UIP patient available. Although 10 out of 11 specimens revealed DAD with hyaline membranes at necropsy, the expression of DAD in the necropsy sample was not associated with the occurrence of an acute exacerbation before death. Ambrosini et al $l^{4}$ found UIP/ $\mathrm{DAD}$ in all seven samples (three surgical and four necroscopic) from IPF/UIP patients with an acute exacerbation. In a study by Parambil and co-workers, ${ }^{20}$ seven patients with IPF underwent a lung biopsy because of an acute exacerbation and a combination of UIP and DAD was observed in five cases; only one patient survived. Kim et $a l^{21}$ found UIP with superimposed DAD in all four cases in whom a surgical lung biopsy specimen was taken at the time of an acute exacerbation. On the other hand, Kondoh et al $l^{5}$ did not find DAD in lung biopsy specimens from patients with an acute exacerbation of IPF classified by their strict criteria. Our results are consistent with these previous studies showing that acute exacerbations of IPF/UIP may lead to DAD. However, our study offers a systematic comparison between specimens taken before and after death from the same patient, regardless of the course of the disease, which enables us to evaluate the true histological variety in necropsy samples and emphasises the fact that DAD is a common feature in UIP, even without an acute exacerbation. Overall, DAD appears to be a very prominent feature of UIP at 
necropsy and is sometimes so strong that it can prevent the histopathological features of UIP being seen in the biopsy specimen. Our study also showed squamous type metaplastic alveolar epithelium in nearly all necropsy samples (10/11), a finding which is not surprising since this type of metaplastic epithelium is known to occur in DAD. ${ }^{4}{ }^{12}$

Other factors associated with acute exacerbations of IPF/ UIP include infection, neutrophilic inflammation, and oxidant stress. Infection could be verified in only four cases in our study, which concurs with one previous study on acute IPF exacerbations. ${ }^{6}$ However, we could not exclude the possibility of lung infections from all of the specimens, so we cannot draw conclusions about lung infection at the terminal phase of IPF/UIP. Nine of the 11 necroscopic lung specimens also contained accumulations of intra-alveolar neutrophils, which is consistent with a previous investigation. ${ }^{6}$ It is also known that activated neutrophils, by generating large amounts of reactive metabolites, may have an important role in the final progression of UIP to DAD. ${ }^{22}$ The predictive role of these mechanisms in IPF/UIP remains unclear, however, and further investigations are required.

This study was carried out retrospectively, which is a valid approach for the study of diseases with a low prevalence such as IPF/UIP. A prospective study would require a very long period of observation. The effect of improvements in health care during the 30 year study period had no significant effect on survival after lung biopsy, which reflects the unresolved clinical problems in treating this disease of unknown aetiology.

In conclusion, the number of FF correlated with the survival and TLCo values of patients with UIP. DAD was a frequent feature in necroscopic specimens from the patients but it did not correlate with the course of the disease or FF. The number of FF in lung biopsy samples taken before death cannot be used as a predictor of acute exacerbations.

\section{ACKNOWLEDGEMENTS}

The authors thank Manu Tuovinen, Juha Tuukkanen, Päivi Koukkula, and Hannu Wäänänen for their technical help.

\footnotetext{
Authors' affiliations

L Tiitto, U Heiskanen, R Kaarteenaho-Wiik, Department of Internal Medicine/Division of Pulmonary Diseases, University of Oulu and Oulu University Hospital, Oulu, Finland

R Bloigu, Medical Informatics Group, University of Oulu and Oulu University Hospital, Oulu, Finland

P Pääkkö, R Kaarteenaho-Wiik, Department of Pathology, University of Oulu and Oulu University Hospital, Oulu, Finland

V L Kinnula, Department of Medicine, Division of Pulmonary Diseases, University of Helsinki and Helsinki University Hospital, Helsinki, Finland

Supported by the Finnish Anti-Tuberculosis Association Foundation, Juselius Foundation, Maud Kuistila Foundation, and funding from Oulu and Helsinki University Hospitals.
}

Competing interests: none declared.

\section{REFERENCES}

1 Carrington CB, Gaensler EA, Coutu RE, et al. Natural history and treated course of usual and desquamative interstitial pneumonia. N Engl J Med 1978;298:801-9.

2 Flaherty KR, Mumford JA, Murray S, et al. Prognostic implications of physiologic and radiographic changes in idiopathic interstitial pneumonia. Am J Respir Crit Care Med 2003;168:543-8.

3 Martinez FJ, Safrin S, Weycker D, et al. The clinical course of patients with idiopathic pulmonary fibrosis. Ann Intern Med 2005;142:963-7.

4 Ambrosini V, Cancellieri A, Chilosi $M$, et al. Acute exacerbation of idiopathic pulmonary fibrosis: report of a series. Eur Respir J 2003;22:821-6.

5 Kondoh Y, Taniguchi H, Kawabata Y, et al. Acute exacerbation in idiopathic pulmonary fibrosis. Analysis of clinical and pathologic findings in three cases. Chest 1993;103:1808-12.

6 Rice AJ, Wells AU, Bouros D, et al. Terminal diffuse alveolar damage in relation to interstitial pneumonias. An autopsy study. Am J Clin Pathol 2003; 119:709-14.

7 King TE Jr, Schwarz MI, Brown K, et al. Idiopathic pulmonary fibrosis: relationship between histopathologic features and mortality. Am J Respir Crit Care Med 2001; 164:1025-32.

8 King TE Jr, Tooze JA, Schwarz Ml, et al. Predicting survival in idiopathic pulmonary fibrosis: scoring system and survival model. Am J Respir Crit Care Med 2001; 164:1171-81.

9 Nicholson AG, Fulford LG, Colby TV, et al. The relationship between individual histologic features and disease progression in idiopathic pulmonary fibrosis. Am J Respir Crit Care Med 2002;166:173-7.

10 Rice AJ, Wells AU, Bouros $D$, et al. Terminal diffuse alveolar damage in relation to interstitial pneumonias. An autopsy study. Am J Clin Pathol 2003;119:709-14.

11 Tiitto L, Heiskanen U, Bloigu R, et al. Thoracoscopic lung biopsy is a safe procedure in diagnosing usual interstitial pneumonia. Chest 2005; 128:2375-80.

12 Travis WD, Colby TV, Koss MN, et al. Non-plastic disorders of the lower respiratory tract. Washington, DC: American Registery of Pathology and the Armed Forces Institute of Pathology, 2002.

13 Dail DH, Hammar SP. Pulmonary pathology. New York: Springer-Verlag, 1994.

14 Wagenvoort CA. Lung biopsy specimens in the evaluation of pulmonary vascular disease. Chest 1980;77:614-25.

15 Akira $M$, Hamada $H$, Sakatani $M$, et al. CT findings during phase of accelerated deterioration in patients with idiopathic pulmonary fibrosis. AJR Am J Roentgenol 1997; 168:79-83.

16 Silcocks PB. Measuring repeatability and validity of histological diagnosis: a brief review with some practical examples. J Clin Pathol 1983;36:1269-75.

17 Armitage P. Statistical methods in medical research, 4th ed. Oxford: Blackwell Science, 2002.

18 Hyde DM, King TE Jr, McDermott T, et al. Idiopathic pulmonary fibrosis. Quantitative assessment of lung pathology. Comparison of a semiquantitative and a morphometric histopathologic scoring system. Am Rev Respir Dis 1992; 146:1042-7.

19 Cherniack RM, Colby TV, Flint A, et al. Quantitative assessment of lung pathology in idiopathic pulmonary fibrosis. The BAL Cooperative Group Steering Committee. Am Rev Respir Dis 1991;144:892-900.

20 Parambil JG, Myers JL, Ryu JH. Histopathologic features and outcome of patients with acute exacerbation of idiopathic pulmonary fibrosis undergoing surgical lung biopsy. Chest 2005;128:3310-5.

21 Kim DS, Park JH, Park BK, et al. Acute exacerbation of idiopathic pulmonary fibrosis: frequency and clinical features. Eur Respir J 2006;27:143-50.

22 Thannickal VJ, Toews GB, White ES, et al. Mechanisms of pulmonary fibrosis. Annu Rev Med 2004;55:395-417.

23 White ES, Lazar MH, Thannickal VJ. Pathogenetic mechanisms in usual interstitial pneumonia/idiopathic pulmonary fibrosis. J Pathol 2003;201:343-54 